
\title{
PREDICTORS OF DENTAL ANXIETY IN CHILDREN: SELF-PERCEPTION
AND PARENTAL FACTORS
}

\author{
ABSTRACT \\ Objectives: To identify the factors involved with dental anxiety in \\ children.
}

Materials and Methods: A cross-sectional study was conducted with children aged 8-12 years and their parents. They were interviewed and examined. Oral health and treatment need perceptions were assessed using a self-reported index. Information about DMFT and dental anxiety scores were collected from children and their parents. Regression analysis was obtained to find association between anxiety in children scores and all variables studied. Spearman's correlation coefficients were calculated to determine possible correlations between variables.

Results: Significant association was observed between the child's oral health self-perception, DMFT and parents' anxiety. It was found a significant correlation between dental anxiety and oral health self perception to children and adults. Moreover, dental anxiety in children is positive correlated to DMFT.

Conclusions: Dental anxiety in children is affected by parental dental anxiety. Moreover, it seems child's dental anxiety is influenced not only by DMFT scores but also by oral health self-perception.

Keywords: Dental anxiety, oral health, self-assessment, child, parents.
*Eloisa Cesario Fernandes ${ }^{1}$

Ana Clara Soares Paiva Tôrres ${ }^{2}$

Fernando José de Oliveira da Nóbrega $^{3}$

(D) Patrícia Bittencourt Santos ${ }^{4}$

ORCID IDs of the authors:

E.C.F. $\quad 0000-0002-9330-1245$

A.C.S.P.T. 0000-0002-7525-3171

F.J.O.N. 0000-0002-0121-0996

P.B.S. 0000-0003-3308-6376

\footnotetext{
${ }^{1}$ Undergraduate Student. Dental School. State University of Rio Grande do Norte, Caico, Brazil.

2 Department of Prosthodontics, State University of Rio Grande do Norte, Caico, Brazil.

${ }^{3}$ Department of Pedodonthics, State University of Rio Grande do Norte, Caico, Brazil.

${ }^{4}$ Department of Pediatric dentistry, State University of Rio Grande do Norte, Caico, Brazil.
} 


\section{INTRODUCTION}

Dental anxiety is a common condition, which can affect people of all ages, mostly children and adolescence. ${ }^{1,2}$ The prevalence of dental anxiety in children varies across international literature ranging from $3 \%$ to $43 \%$ depending on populations and age groups. The development of dental anxiety has a multifactorial and not wellknown background. It can influence patient management, dental attendance and can persist even in adulthood, leading to dental avoidance. ${ }^{3,4}$

Existing evidence about parental effect and oral health condition on anxiety in children are conflicting. Even though many studies have showed a positive correlation between those and dental anxiety. ${ }^{5,6,7}$ It seems there is a vicious circle, in which children with dental anxiety are more prone to delaying their treatment, thereby leading to worsening of their problems and fueling the dental anxiety that was already present. ${ }^{8}$

Patient perception of oral condition has multidimensional nature and it is not only influenced by clinical conditions but also by psychosocial features, as dental anxiety. ${ }^{9}$ People with dental anxiety can report a negative perception about their oral health influenced by misconceptions about dental treatment, regardless of their real context. ${ }^{10}$

Identifying potentially modifiable factors that may affect the interaction between the negative selfperception and clinical status is crucial to achieve a patient management success. Therefore, assessing the background of anxiety in children can determine the most appropriate and effective management strategy. So, the dentist plays an important role in decreasing or eliminating dental anxiety in the patient and promoting good general oral hygiene habits..$^{10,11}$

\section{MATERIAL AND METHODS}

\section{Study design and subjects}

The study participants included 230 people, who were 115 school-children (51 girls, 64 boys) ranging 8-12 years old from schools and 115 respective parents (81 mothers 34 fathers). The average children's age was 9.2 years $(\mathrm{SD}=1.2)$.

From August 2015 to August 2017, data were collected from children enrolled in public schools. Sample was selected including all schools of the city. In each school, all children ranging 8-12 years were invited to participate, and their parents as well. Children and their parents who agreed were included in the data collection at school, which consisted of an interview and clinical oral examination.

A member of the research team explained the questionnaire instructions to the children and their parents, who individually completed each assessment. Moreover, a researcher was available for further clarification or explanation of the survey whether needed.

Informed consent from parents and school staff was obtained for all participants. This study received ethical approval from the local ethics committee of authors institutions (No. 1448908).

\section{Dental anxiety scores}

An adaptation of the 5-item Modified Dental Anxiety Scale (MDAS) for the Portuguese language was used to all adults. Participants reported levels of dental anxiety on a 5-point Likert scale, with 1 meaning, 'relaxed/not worried' and 5 meaning, 'very nervous/very worried'. ${ }^{12}$

Faces representing the level of anxiety were included on the Likert scale to facilitate the children's understanding of the questionnaire items (MDAS(f)). A total score was calculated by adding the child's responses, which ranged from 5 to 25 (higher scores reflected greater anxiety levels). ${ }^{13}$

Dental health status: An experienced paediatric dentist conducted a clinical examination and determined the dental status of each participant using a flat-surface mouth mirror and gauze. The index for decayed, missed and filled primary teeth (dmft), and permanent teeth (DMFT) were recorded. ${ }^{14}$

Self-assessed oral health status: Children and their parents were asked, 'How would you describe your dental status?' The response format included three options: Good, Fair or Bad.

Treatment need perception: Those information were obtained from the question: "As for today, in your opinion, how many treatments do you need?" 
The response format included three options: A lot, Some or Not at all.

\section{Data analysis}

The data obtained on the questionnaires and scales were analyzed with the aid of the Statistical Package for the Social Sciences (SPSS ${ }^{\circledR}$, Version 15.0, Chicago, USA). Regression analysis was obtained trying to find association between anxiety in children scores and all variables studied. Spearman's correlation coefficients were calculated to determine possible correlations

Table 1. Descriptive analysis of the investigated variables

Table 1. Descriptive analysis of the investigated variables

Variables

Subjects

\begin{tabular}{|c|c|c|c|}
\hline & Average & & Sd \\
\hline Child's Anxiety & 20.57 & & 5.69 \\
\hline Parental Anxiety & 11.32 & & 4.56 \\
\hline Dmft & 3.83 & & 1.75 \\
\hline \multirow{3}{*}{ Dmft } & 6.42 & & 2.38 \\
\hline & \multicolumn{3}{|c|}{ Percentual Of Subjects } \\
\hline & Good & Fair & Bad \\
\hline Child's Self-Assessed Oral Health Status & $32(28 \%)$ & $75(65 \%)$ & $8(7 \%)$ \\
\hline \multirow[t]{2}{*}{ Parental Self-Assessed Oral Health Status } & $44(38 \%)$ & $65(56 \%)$ & $6(6 \%)$ \\
\hline & Not At All & Some & A Lot \\
\hline Child's Treatment Need Perception & $30(26 \%)$ & $71(62 \%)$ & $14(12 \%)$ \\
\hline Parental Treatment Need Perception & $34(30 \%)$ & $66(57 \%)$ & $15(13 \%)$ \\
\hline
\end{tabular}

Association between anxiety in children and all independent variables is shown in Table 2 . Significant association was observed in the analysis between the child's oral health self- between variables. The level of significance was set to $5 \%(\mathrm{P} \leq 0.05)$.

\section{RESULTS}

A hundred fifteen children and their parents were included in this study. Mean of dental anxiety in children and their parents was 20.57 and 11.32, respectively. Table 1 shows the distribution of the sample and descriptive analyses to all variables. Most of all people consider their dental health needs to be 'some', and dental status to be 'fair'. perception, dtmf and parental anxiety, considering anxiety in children as dependent variable $(\mathrm{P}<0.005)$.

Table 2 - Results of multiple linear regression analysis, considering child anxiety as the dependent variable.

Variables

Parental Anxiety

Dmft

Dmft

Child's Self-Assessed Oral Health Status

Parental Self-Assessed Oral Health Status

Child's Treatment Need Perception

Parental Treatment Need Perception

$\mathrm{R}=0.468$
Child's Anxiety

$\mathrm{P}$
$0.016^{*}$
$0.001 *$
0.074
$0.039 *$
0.479
0.151
0.903
$\mathrm{R} 2=0.219$

*Statistically significant at $\mathrm{P}<0.05$. 
The data also demonstrate a significant correlation between dental anxiety and oral health self-perception to children and adults. Moreover, children's dental anxiety is positive correlated to
DMFT. To all people, oral health self-perception is correlated to treatment need perception (Tables 3 and 4).

Table 3. Correlation coefficients among parental anxiety, DMFT index, Self-assessed oral health status and treatment need perception - Spearman's (r) correlation coefficients.

\begin{tabular}{|c|c|c|c|c|}
\hline Variable & Parental Anxiety & Dmft & $\begin{array}{c}\text { Parental Self-Assessed } \\
\text { Oral Health Status } \\
\end{array}$ & $\begin{array}{c}\text { Parental Treatment } \\
\text { Need Perception }\end{array}$ \\
\hline \multicolumn{5}{|l|}{ Parental Anxiety } \\
\hline Dmft & $\begin{array}{c}0.0626 \\
\mathrm{P}=0.510\end{array}$ & & & \\
\hline \multirow[t]{2}{*}{$\begin{array}{l}\text { Parental Self-Assessed Oral } \\
\text { Health Status }\end{array}$} & -0.2041 & -0.1507 & & \\
\hline & $\mathrm{P}=0.030^{*}$ & $\mathrm{P}=0.111$ & & \\
\hline \multirow[t]{2}{*}{$\begin{array}{l}\text { Parental Treatment Need } \\
\text { Perception }\end{array}$} & -0.0237 & -0.2136 & 0.3866 & \\
\hline & $\mathrm{P}=0.803$ & $\mathrm{P}=0.023 *$ & $\mathrm{P}=0.000 *$ & \\
\hline
\end{tabular}

*Statistically significant at $\mathrm{P}<0.05$.

Table 4. Correlation coefficients among children's Anxiety, dmft index, Self-assessed oral health status and Treatment need perception - Spearman's (r) correlation coefficients.

\begin{tabular}{|c|c|c|c|c|}
\hline Variable & Child's Anxiety & DMFT & $\begin{array}{c}\text { Child's Self-Assessed } \\
\text { Oral Health Status }\end{array}$ & $\begin{array}{l}\text { Child's Treatment } \\
\text { Need Perception }\end{array}$ \\
\hline \multicolumn{5}{|l|}{ Child's Anxiety } \\
\hline \multirow{2}{*}{ DMFT } & 0.3162 & & & \\
\hline & $\mathrm{P}=0.001 *$ & & & \\
\hline \multirow{2}{*}{$\begin{array}{l}\text { Child's Self-Assessed } \\
\text { Oral Health Status }\end{array}$} & -0.1953 & -0.1777 & & \\
\hline & $\mathrm{P}=0.038^{*}$ & $\mathrm{P}=0.060$ & & \\
\hline \multirow[t]{2}{*}{$\begin{array}{l}\text { Child's Treatment Need } \\
\text { Perception }\end{array}$} & 0.095 & -0.0191 & 0.3968 & \\
\hline & $\mathrm{P}=0.312$ & $\mathrm{P}=0.841$ & $\mathrm{P}=0.000 *$ & \\
\hline
\end{tabular}

\section{DISCUSSION}

Dentists should know more about aetiology of anxiety to gain a better understanding of it and therefore to help paediatric patients and their families to cope with dental anxiety. Indeed, the evaluation of anxiety should be part of a paediatric anamnesis. ${ }^{15,16,17}$ An understanding of psychologic and behavioural sciences has long been a central part of dental education and essential for a better clinical practice. Patients who have anxiety regarding their dental health and treatment needs, tend to delay appointments and avoidance behaviour towards oral care.18 For this reason, evaluation of anxiety levels and treatment needs can be supportive for a good oral health maintenance and psychological improvement of children. Once child behaviour is changed, it is possible to prevent not only diseases, but also help to streamline appropriate oral hygiene habits and regular dental appointment. ${ }^{12,19,20}$

There are many instruments available for the assessment of dental anxiety, both in children and adults. In this study, the Modified Dental Anxiety Scale ${ }^{12}$, a reliable and quick five item scale to administer was adopted for all parents. It has a scale ranging between mild, moderate, and phobic levels of anxiety. ${ }^{21}$ Although there are some measures which allow for the particular identification of characteristics of the individual's dental anxiety, the MDAS provides a quick and easy-to-use screening tool. It has been found to be acceptable both to patients and dentists. ${ }^{22-24}$ 
A version is also available for use with children $^{25}$ (Modified Child Dental Anxiety Scale, MCDAS), although there are various scales and techniques used in order to assess anxiety in children. In the current study, anxiety in children rates were recorded by MCDAS - faces ${ }^{13}$, as it has been shown to be reliable and valid scale. ${ }^{1,26,27}$ Since children are limited by the level of cognitive functioning required to complete the various other numeric rating scales, we understand a selfreported and an easy index for children are necessary. ${ }^{28}$ The faces version of the MCDAS has been tested in a series of studies with children. Aminabadi et al. ${ }^{29}$ and Fakhruddin et al.30 have also used this scale for recording anxiety in their studies. ${ }^{31,32}$ And a good test-retest reliability was demonstrated in children between 8 and 12 years old. $^{13}$

The aetiology of dental anxiety is believed to be multifactorial with sociodemographic status playing important roles as risk factor. ${ }^{33}$ That means homogeneity of children and parents in terms of sociodemographic issues is crucial to avoid confounding factors. In this study, only one type of school was included to obtain a better representation of children and their parents, regarding economic and demographic factors. This aspect reinforces the robustness of our results.

An understanding of the factors underlying the aetiology and maintenance of dental anxiety and how children learn it may assist dentists to reduce this fear in children. It has been suggested that fears are learned by observing the behaviour of other individuals and the outcomes of those behaviour. Parents usually serve as a model for development of anxiety, and parental behaviour towards oral health may be considered a modelling process in which children imitate adult models. ${ }^{34-37}$

In the present study, associations were found between the children and parents' dental anxiety scores, although both showed lower dental anxiety score. That lower anxiety score was unreported in other studies, although no information was shared about dental experience, history of dental phobia, history of dental pain, and diagnosed behaviour disorders. ${ }^{10,38-41}$ Those aspects are known to cause dental anxiety. ${ }^{42}$ Our findings indicate the parents had an influence on anxiety in children level, in a good or bad way. Indeed, negative or positive dental attitudes and experiences transmitted by parents are related somehow to anxiety in children, even though there is not an agreement in the international data about this finding. Previous studies report no association between parental and MCDAS scores ${ }^{37,41,43-45}$, whereas others found that parental anxiety was associated with children anxiety. $3,46,47$

That difference can be explained by the fact that mothers are usually more involved in childcare. ${ }^{37}$ Our findings showed the children were most often accompanied by their mothers during dental care $(70,44 \%)$. Previous studies found that maternal anxiety level was predictive of dental anxiety score in children, and these findings are supported with our results. ${ }^{15,37,48}$

A recent literature review ${ }^{49}$ suggested that parental dental anxiety may affect child dental anxiety by transmission of anxiety model and verbal learning that it would cause decreased selfefficacy for pain and affect perceptions of dental stimuli. Moreover, parental anxiety could also impact a child's learning history when it results in avoidance of dental appointments.

Self-reported measures regarding oral health and treatment need are cost- and timeeffective. ${ }^{50,51}$ It is hypothesized that they can give an opportunity to determine dental health for a single person and populations also. This kind of evaluation can help people who avoid clinical examination, for reason of either cost or fear of embarrassment of their oral condition. ${ }^{18,52}$

Our findings show there is no correlation between DMFT/dmft scores and self-reported dental status for children and their parents. In general, the present study results indicate that most of the children and their parents consider their dental health needs to be 'some', and dental status to be 'fair' which it was also reported before. ${ }^{18}$ Even though, people tend to underestimate their dental treatment needs ${ }^{53}$, 
possibly that is why those variables were not correlated.

On the other hand, it was found a positive correlation between self-reported dental health needs and oral health dental status. It was stated that the use of patient self-assessment was a good predictor of patient dental status and it could serve as a tool for public and preventive dentistry, as well as to help the dental practitioner in managing patients according to their complaints and selfassessment. ${ }^{50}$ According to the results of this study, simply asking straightforward questions regarding child's dental status may predict the results of their dental anxiety. Tables 3 and 4 show that the dental status self-perception is positive correlated to dental anxiety for children and adults. Once there is a tendency toward a correlation between the dental anxiety and the need for dental treatment shows that, despite minimally invasive dentistry, dentist's appointment remains closely associated with unpleasant experiences. ${ }^{15,54,55}$

Hence, it is reasonable to understand that since children found their oral health status fair, their dental anxiety score was also small. ${ }^{56}$

It is recognized that dental anxiety is associated with irregular dental attendance ${ }^{48,57,58}$, which can head to a poor oral health, with a higher incidence of caries lesions in children with dental anxiety. ${ }^{57,59-61}$ It is important that dentists must consider that dental fear may also affect oral health self-perception. Our results show that children dental anxiety is directly affected by their oral health and also by their self-perception about oral health status. That means dental anxiety is likely to be a predictor of dental caries, and may be a risk factor for dental caries and incidence. ${ }^{61}$ Tables 4 also shows a positive correlation. In this sample, the more the children caries experience, the more dental anxiety in children was significantly higher. That can be explained since dental anxiety children might perceive that dentists will only provide symptomatic care for their declining oral health, rather than a comprehensive treatment. This behaviour is most likely related to their previous negatively perceived experiences. ${ }^{62}$ De Jongh et al. ${ }^{48}$, confirmed that avoidance of dental care is related to a worse oral health and likelihood of experiencing anxiety. Besides, it was suggested that patients with high dental anxiety would particularly benefit from minimal interventions to break their avoidance pattern. ${ }^{37,48}$

\section{CONCLUSIONS}

We suggest family factors may serve to help determine the pattern of learning in which child's dental anxiety is affected by their parental dental anxiety. Moreover, it seems children's dental anxiety is influenced not only by DMFT scores but also by the oral health self-perception.

\section{ACKNOWLEDGMENT}

The authors would like to acknowledge National Council for Scientific Development (CNPq) for its Support.

\section{REFERENCES}

1. Porritt J, Marshman Z, Rodd HD. Understanding children's dental anxiety and psychological approaches to its reduction. Int J Paediatr Dent 2012;22:397-405.

2. Buldur B, Armfield JM. Development of the Turkish version of the Index of Dental Anxiety and Fear (IDAF-4C+): Dental anxiety and concomitant factors in pediatric dental patients. $\mathrm{J}$ of Clin Pediatr Dent 2018;42:279-286.

3. Boka V, Arapostathis K, Kotsanos N, Karagiannis V, van Loveren C, Veerkamp J. Relationship between Child and Parental Dental Anxiety with Child's Psychological Functioning and Behavior during the Administration of Local Anesthesia. J Clin Pediatr Dent 2016;40:431-437.

4. Buldur B, Guvendi ON. Conceptual modelling of the factors affecting oral health-related quality of life in children: A path analysis. Int J Paediatr Dent 2020;30181-192

5. Busato P, Garbín RR, Santos CN, Paranhos LR, Rigo L. Influence of maternal anxiety on child anxiety during dental care: cross-sectional study. Med J. 2017;135:116-122.

6. Daniel W, McNeil, Cameron L, Randal, Lindsey L, Cohen, Richard J, Crout. Robert J, Weyant, Katherine Neiswanger, Mary L, Marazita. Transmission of dental fear from parent to adolescent in an Appalachian sample in the USA. Int J Paediatr Dent 2019;29:720727. 
7. Mohebbi SZ, Razeghi S, Gholami M, Kharazifard MJ, Rahimian S. Dental fear and its determinants in 711-year-old children in Tehran, Iran. Eur Arch Paediatr Dent 2019;20:393-401.

8. Armfield JM, Stewart JF, Spencer AJ. The vicious cycle of dental fear: exploring the interplay between oral health, service utilization and dental fear. BMC Oral Health 2007;7:1.

9. Buldur B. Angel or Devil? Dentists and Dental Students Conceptions of Pediatric Dental Patients through Metaphor Analysis. J Pediatr Dent 2018;42:119-124.

10. Goettems ML, Ardenghi TM, Romano AR, Demarco FF, Torriani DD. Influence of maternal dental anxiety on oral health-related quality of life of preschool children. Qual Life Res 2011;20:951-959.

11. Liu Y, Gu Z, Wang Y, et al. Effect of audiovisual distraction on the management of dental anxiety in children: A systematic review. Int J Paediatr Dent 2019;29:14-21.

12. Humphris GM, Morrison T, Lindsay SJ. The Modified Dental Anxiety Scale: validation and United Kingdom norms. Community Dent Health 1995; 12:143-150.

13. Howard KE, Freeman R. Reliability and validity of a faces version of the Modified Child Dental Anxiety Scale. Int J Paediatr Dent 2007;17:281-288.

14. Organizaation WH. Oral health surveys: basic methods. Vol 4th. Geneva: Switzerlan: Word Health Organization.

15. Assuncão CM, Losso EM, Andreatini R, de Menezes JV. The relationship between dental anxiety in children, adolescents and their parents at dental environment. J Indian Soc Pedod Prev Dent 2013;31:175-179.

16. Moore R, Brødsgaard I. Dentists' perceived stress and its relation to perceptions about anxious patients. Community Dent Oral Epidemiol 2001;29:73-80.

17. Buldur B. Behavior Management in Pediatric Dentistry: An Overview and Interpretation. Pesquisa Brasileira em Odontopediatria e Clínica Integrada 2019; 19:e4649-4650

18. Buldur B. Pathways between parental and individual determinants of dental caries and dental visit behaviours among children: Validation of a new conceptual model. Community Dent Oral Epidemiol 2020;48:280-287
19. Syed S, Bilal S, Dawani N, Rizvi K. Dental anxiety among adult patients and its correlation with selfassessed dental status and treatment needs. J Pak Med Assoc 2013;63:614-618.

20. Honkala E. Oral health promotion with children and adolescents. In. New York: Oxford University Press: Oral Health Promotion 1993;1:169-187.

21. King K, Humphris GM. Evidence to confirm the cutoff for screening dental phobia using the Modified Dental Anxiety Scale. Soc Sci Dent 2010;1:21-28.

22. Humphris GM, Clarke HM, Freeman R. Does completing a dental anxiety questionnaire increase anxiety? A randomised controlled trial with adults in general dental practice. Br Dent J 2006;201:33-35.

23. Hull P, Humphris G. Anxiety reduction via brief intervention in dentally anxious patients: a randomised controlled trial. Soc Sci Dent 2010;1:108-117.

24. Newton T, Asimakopoulou K, Daly B, Scambler S, Scott S. The management of dental anxiety: time for a sense of proportion? Br Dent J 2012;213:271-274.

25. Freud A. Normality and Pathology in Childhood. London: Karnac Books; 1989.

26. El-Housseiny AA, Alamoudi NM, Farsi NM, El Derwi DA. Characteristics of dental fear among Arabic-speaking children: a descriptive study. BMC Oral Health 2014;14:118.

27. El-Housseiny AA, Alsadat FA, Alamoudi NM, Douaa A ED, Najat MF, Moaz HA, Basil MA. Reliability and validity of the Children's Fear Survey Schedule-Dental Subscale for Arabic-speaking children: a cross-sectional study. BMC Oral Health 2016;16:49.

28. Niharika P, Reddy NV, Srujana P, Srikanth K, Daneswari V, Geetha KS. Effects of distraction using virtual reality technology on pain perception and anxiety levels in children during pulp therapy of primary molars. J Indian Soc Pedod Prev Dent 2018;36:364-369.

29. Aminabadi NA, Pourkazemi M, Babapour J, Oskouei SG. The impact of maternal emotional intelligence and parenting style on child anxiety and behavior in the dental setting. Med Oral Patol Oral Cir Bucal 2012;17:1089-1095. 
30. Fakhruddin KS, El Batawi H, Gorduysus MO. Effectiveness of audiovisual distraction eyewear and computerized delivery of anesthesia during pulp therapy of primary molars in phobic child patients. Eur J Dent 2015;9:470-475.

31. Neverlien PO. Dental anxiety, optimismpessimism, and dental experience from childhood to adolescence. Community Dent Oral Epidemiol 1994;22:263-268.

32. Wright FA. Relationship of children's anxiety to their potential dental health behaviour. Community Dent Oral Epidemiol 1980;8:189-194.

33. Folayan MO, Idehen EE, Ufomata D. The effect of sociodemographic factors on dental anxiety in children seen in a suburban Nigerian hospital. Int $\mathbf{J}$ Paediatr Dent 2003;13:20-26.

34. Do C. Applying social learning theory to children with dental anxiety. J Contemp Dent Pract 2004;5:126135 .

35. Rachman S. The conditioning theory of fearacquisition: a critical examination. Behav Res Ther 1977;15:375-387.

36. Okada M, Kawamura M, Kaihara Y, Matsuzaki Y, Kuwahara S, Ishidori H, Miura K. Influence of parents' oral health behaviour on oral health status of their school children: an exploratory study employing a causal modelling technique. Int $\mathrm{J}$ Paediatr Dent 2002;12:101-108.

37. Coric A, Banozic A, Klaric M, Vukojevic K, Puljak L. Dental fear and anxiety in older children: an association with parental dental anxiety and effective pain coping strategies. J Pain Res 2014;7:515-521.

38. Klingberg G, Broberg AG. Dental fear/anxiety and dental behaviour management problems in children and adolescents: a review of prevalence and concomitant psychological factors. Int $\mathrm{J}$ Paediatr Dent. 2007;17:391-406.

39. Davey GC. Dental phobias and anxieties: evidence for conditioning processes in the acquisition and modulation of a learned fear. Behav Res Ther 1989;27:51-58.

40. Hardy DF, Power TG, Jaedicke S. Examining the relation of parenting to children's coping with everyday stress. Child Dev 1993;64:1829-1841.
41. Leal AM, Serra KG, Queiroz RC, Araújo MA, Maia Filho EM. Fear and/or anxiety of children and parents associated with the dental environment. Eur J Paediatr Dent 2013;14:269-272.

42. Lee DW, Kim JG, Yang YM. The Influence of Parenting Style on Child Behavior and Dental Anxiety. Pediatr Dent 2018;40:327-333.

43. Arapostathis KN, Coolidge T, Emmanouil D, Kotsanos N. Reliability and validity of the Greek version of the Children's Fear Survey Schedule-Dental Subscale. Int J Paediatr Dent 2008;18:374-379.

44. Ten Berge M, Veerkamp JS, Hoogstraten J. The etiology of childhood dental fear: the role of dental and conditioning experiences. J Anxiety Disord 2002;16:321-329.

45. Nuttall NM, Gilbert A, Morris J. Children's dental anxiety in the United Kingdom in 2003. J Dent 2008;36:857-860.

46. Milgrom P, Jie Z, Yang Z, Tay KM. Cross-cultural validity of a parent's version of the Dental Fear Survey Schedule for children in Chinese. Behav Res Ther 1994;32:131-135.

47. Klaassen MA, Veerkamp JS, Aartman IH, Hoogstraten J. Stressful situations for toddlers: indications for dental anxiety? ASDC J Dent Child 2002;69:306-309.

48. De Jongh A, Schutjes M, Aartman IH. A test of Berggren's model of dental fear and anxiety. Eur J Oral Sci 2011;119:361-365.

49. Seligman LD, Hovey JD, Chacon K, Ollendick TH. Dental anxiety: An understudied problem in youth. Clin Psychol Rev 2017;55:25-40.

50. Samorodnitzky GR, Levin L. Self-assessed dental status, oral mo, DMF, and dental anxiety. J Dent Educ 2005;69:1385-1389.

51. Pitiphat W, Garcia RI, Douglass CW, Joshipura KJ. Validation of self-reported oral health measures. J Public Health Dent 2002;62:122-128.

52. Gilbert AD, Nuttall NM. Self-reporting of periodontal health status. Br Dent J 1999;186:241-244.

53. Bamigboye O, Akande TM. Oral Hygiene Status of Students in Selected Secondary Schools in Osogbo, Nigeria. Medical Practitioner 2007;51:71-75. 
54. Stenebrand A, Boman WU, Hakeberg M. Dental anxiety and temperament in 15-year olds. Acta Odontologica Scandinavica 2013;71:15-21.

55. Bottan ER, Oglio JD, De Araujo SM. Dental Anxiety in Elementary Schoolchildren. Pesq Bras Odontoped Clin Integr 2007;7.

56. Rodrigues F, Rebouças AG, Flório FM. Selfperception of oral health among schoolchildren in a city of Amazonas, Brazil: related factors. Rev Gaúch Odontol 2017;65:44-51.

57. Coriat IH. Dental anxiety; fear of going to the dentist. Psychoanal Rev 1946;33:365-367.

58. Lazarus RS. Coping theory and research: past, present, and future. Psychosom Med 1993;55:234-247.
59. Curry SL, Russ SW. Identifying coping strategies in children. J Clin Child Psychol. 1985;14:61-69.

60. Smith PA, Freeman R. Remembering and repeating childhood dental treatment experiences: parents, their children, and barriers to dental care. Int J Paediatr Dent 2010;20:50-58.

61. Coric A. Association between Dental Anxiety and Oral Health. 2011.

62. Lara A, Crego A, Romero-Maroto M. Emotional contagion of dental fear to children: the fathers' mediating role in parental transfer of fear. Int J Paediatr Dent 2012;22:324-330. 